\title{
Oxidation and phase transitions of epitaxial tin oxide thin films on (1012) sapphire
}

\author{
X. Q. Pan ${ }^{\text {a) }}$ and L. Fu \\ Department of Materials Science and Engineering, The University of Michigan, Ann Arbor, Michigan 48109
}

(Received 11 September 2000; accepted for publication 5 March 2001)

We studied the structural behavior and electrical transport properties of epitaxial $\alpha$-SnO thin films grown on the (1012) $\alpha-\mathrm{Al}_{2} \mathrm{O}_{3}$ (sapphire) substrate. Hall effect measurements revealed that the epitaxial as-deposited $\mathrm{SnO}$ film is a $p$-type semiconductor. In situ $\mathrm{x}$-ray diffraction studies show that the $\alpha$-SnO phase is metastable and will transform into $\mathrm{SnO}_{2}$ with the rutile type structure when annealed at high temperatures in air. The onset of this phase transformation was observed to begin approximately at $300^{\circ} \mathrm{C}$ during heating. Shortly thereafter, rutile $\mathrm{SnO}_{2}$ was observed to coexist with $\alpha$-SnO and intermediate products such as $\mathrm{Sn}$ and $\mathrm{Sn}_{3} \mathrm{O}_{4}$. After being annealed at temperatures above $600{ }^{\circ} \mathrm{C}$, the film then fully transformed into the rutile $\mathrm{SnO}_{2}$ phase. Our results show that the $\alpha$-SnO to $\mathrm{SnO}_{2}$ structural transformation proceeds initially by the localized disproportionate redistribution of internal oxygen at low temperature, followed by the transformation of the remaining $\mathrm{SnO}$ phase and intermediate phases into $\mathrm{SnO}_{2}$ via the inward diffusion of external oxygen at higher temperatures. Most of the $\mathrm{SnO}_{2}$ crystallites nucleate epitaxially on $\alpha$-SnO with the orientation relationship of $(101)_{\mathrm{SnO}_{2}} / /(001)_{\mathrm{SnO}}$ and their growth processes are controlled by the $(101)_{\mathrm{SnO}_{2}} / /(001)_{\mathrm{SnO}}$ interfaces, leading to a (101) texture and a laminar grain shape for $\mathrm{SnO}_{2}$. The relationship between the electrical transport properties and the structural evolution of the film has also been investigated. (C) 2001 American Institute of Physics. [DOI: 10.1063/1.1368865]

\section{INTRODUCTION}

Tin dioxide $\left(\mathrm{SnO}_{2}\right)$ with the rutile type structure is an $n$-type wide band-gap semiconductor. Due to its outstanding electrical, optical, and electrochemical properties, $\mathrm{SnO}_{2}$ has a wide range of applications in solar cells, catalytic support materials, transparent electrodes, and solid state chemical sensors. ${ }^{1,2} \mathrm{SnO}_{2}$ is widely used as a base material in gas alarms on domestic, commercial, and industrial premises due to its high sensitivity to small concentrations of gases (at ppm levels). In particular, $\mathrm{SnO}_{2}$ thin films have drawn much interest because of their potential application in transparent electrodes for solid state display and microelectronic gas sensing devices. ${ }^{3}$ Considerable attention has recently focused on the development of solid state gas sensors based on nanocrystalline thin films. ${ }^{4-10}$

Physical vapor deposition (PVD) methods have been widely used for the fabrication of tin oxide thin films. ${ }^{11-15}$ $\mathrm{SnO}_{2}$ ceramics are commonly used as source material. Under high vacuum conditions and at high temperatures, the gaseous $\mathrm{SnO}_{2}$ molecules will dissociate and the film material condensed onto the substrate is primarily oxygen deficient. Previous studies ${ }^{16,17}$ have shown that films deposited at low substrate temperatures (below $300{ }^{\circ} \mathrm{C}$ ) are amorphous, while films grown above $350^{\circ} \mathrm{C}$ have a crystalline $\alpha$-SnO structure. Such oxygen-deficient phases are metastable in air. A postdeposition annealing in oxygen atmosphere is required in order to obtain a rutile $\mathrm{SnO}_{2}$ film.

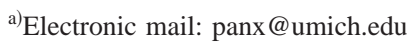

The postdeposition annealing process has a strong influence on the microstructure, chemical composition, and electrical transport properties of the resulting $\mathrm{SnO}_{2}$ films. Geurts et al. ${ }^{18}$ used Raman scattering, IR reflectivity measurements, and $\mathrm{x}$-ray diffraction (XRD) to examine the oxidation process that converts electron beam evaporated $\mathrm{SnO}$ films into $\mathrm{SnO}_{2}$. They concluded that the oxidation process began with the formation of $\mathrm{SnO}_{2}$ and other intermediate phases, such as $\mathrm{Sn}_{3} \mathrm{O}_{4}$ and metallic $\mathrm{Sn}$, via internal oxygen disproportionate allocation, which was then followed by external oxygen indiffusion to complete the transformation. Reddy et al. ${ }^{16}$ reported that electron-beam evaporated tin oxide films transform into the final oxidation state $\mathrm{SnO}_{2}$ either through the single oxidation state $\mathrm{SnO}$ or through two oxidation states, namely $\mathrm{SnO}$ and $\mathrm{Sn}_{3} \mathrm{O}_{4}$, depending on the film deposition temperature. Soares et al. ${ }^{19}$ studied tin oxide films prepared by reactive sputtering using Mössbauer spectroscopy. They found that films grown with low oxygen pressure retained a certain amount of $\mathrm{SnO}$ even after annealing at $600^{\circ} \mathrm{C}$, while those deposited at high oxygen pressure were completely transformed to $\mathrm{SnO}_{2}$ even though they were annealed at the same temperature.

Although many studies have been reported on the annealing process of $\mathrm{SnO}_{x}$ films, the $\alpha-\mathrm{SnO}-\mathrm{SnO}_{2}$ phase transformation mechanisms are still unclear. In particular, little work has been done on the influence of the oxidation processes on the microstructure, crystal defect configurations, and electrical transport properties of the resulting $\mathrm{SnO}_{2}$ thin films. This knowledge is crucial to establish the structureproperty relationships of $\mathrm{SnO}_{2}$ thin films. In the present study, epitaxial $\mathrm{SnO}$ thin films were deposited on sapphire 
substrates and their structural evolution during annealing at high temperatures in air were investigated by in situ x-ray diffraction, transmission electron microscopy (TEM), x-ray photoelectron spectroscopy, and Hall effect measurements using the van der Pauw method. The structure-property relationships of the $\mathrm{SnO}$ during the transformation processes has been established based on the experimental observations.

\section{EXPERIMENTAL METHODS}

$\mathrm{SnO}$ thin films were deposited on (T-012) $\alpha-\mathrm{Al}_{2} \mathrm{O}_{3}$ (sapphire) substrates by the electron beam evaporation of $\mathrm{SnO}_{2}$ ceramic source. The disks of $\mathrm{SnO}_{2}$ ceramic were prepared by sintering a high purity $\mathrm{SnO}_{2}$ powder synthesized by chemical coprecipitation. A detailed description of the experimental procedure is given elsewhere. ${ }^{17}$ The substrate materials used in this study were single-crystal $\alpha-\mathrm{Al}_{2} \mathrm{O}_{3}$ with a (1012) surface orientation (R-cut). After loading the substrate into the deposition chamber, the system was pumped down to approximately $5.0 \times 10^{-8}$ Torr. During deposition, the background pressure in the chamber was about $10^{-6}$ Torr. Films were deposited at $600{ }^{\circ} \mathrm{C}$ with a nominal film thickness around $1000 \AA$. A quartz crystal oscillator installed within the deposition chamber was used to measure the deposition rate and film thickness during deposition. The film thickness measurement was ascertained by cross-section TEM. The deposition rate for this study was $0.4 \AA / \mathrm{s}$.

In situ X-ray diffraction (XRD) studies were carried out on a Rigaku diffractometer using $\mathrm{Cu} K \alpha$ radiation. Samples were oxidized at high temperature in air. Some of the XRD studies at room temperature were conducted on a rotating anode four-circle diffractometer (Rigaku, Japan). TEM examinations were conducted in a JEOL 4000EX highresolution transmission electron microscope (HRTEM) equipped with a Gatan imaging filter (GIF). The microscope was operated at $400 \mathrm{kV}$, which provides a point-to-point resolution of $0.17 \mathrm{~nm}$. Cross-sectional TEM specimens were prepared by a standard procedure, which includes mechanical grinding, polishing, precision dimpling, and ion milling. The final thinning of specimens was carried out on a Gatan precision ion polishing system (PIPS ${ }^{\text {TM }}$, Model 691) using an accelerating voltage of $4.5 \mathrm{kV}$ and an incident angle of $4^{\circ}-$ $6^{\circ}$. X-ray photoelectron spectroscopic (XPS) studies were performed on a PHI 5400 XPS system (Perkin-Elmer Corporation, $\mathrm{MN})$. All spectra were recorded under vacuum condition better than $10^{-9}$ Torr. The electrical properties of the thin films were determined by Hall effect measurements in a $2.5 \times 10^{3}$ Gauss magnetic field using the van der Pauw method.

\section{RESULTS}

As reported in previous work, ${ }^{17}$ an epitaxial $\alpha$-SnO thin film can be fabricated on a $(\overline{1012})$ sapphire $\left(\alpha-\mathrm{Al}_{2} \mathrm{O}_{3}\right)$ substrate by electron beam evaporation deposition at $600{ }^{\circ} \mathrm{C}$ using a ceramic $\mathrm{SnO}_{2}$ source. As-deposited epitaxial $\alpha$-SnO film was loaded into a hot-stage for in situ XRD study. X-ray diffraction patterns were recorded at various temperatures between room temperature and $700{ }^{\circ} \mathrm{C}$ during heating in air.

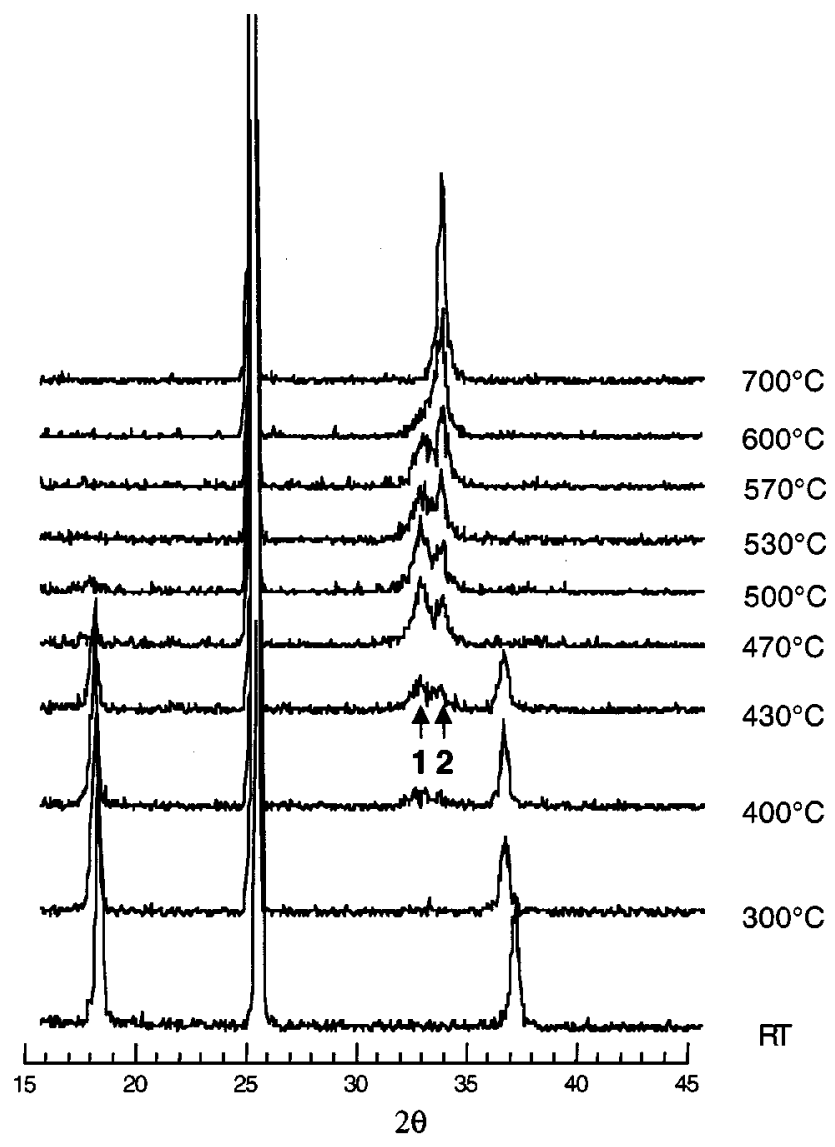

FIG. 1. In situ XRD spectra showing the phase transformation from $\mathrm{SnO}$ to $\mathrm{SnO}_{2}$. The strong reflection peak around $25^{\circ}$ is from substrate. Peak 1 is from $\mathrm{Sn}_{3} \mathrm{O}_{4}$ (003) and peak 2 is from $\mathrm{SnO}_{2}$ (101).

Figure 1 shows XRD patterns of the film recorded at different temperatures upon heating. All diffraction patterns were recorded in a $2 \theta$ range of $15^{\circ}-85^{\circ}$. However, only data from $15^{\circ}$ to $45^{\circ}$ is shown in Fig. 1 since no useful information exists from $45^{\circ}$ to $85^{\circ}$. The first diffraction pattern was taken at room temperature before heating. The film was slowly heated to $300{ }^{\circ} \mathrm{C}$ and held at this temperature for $1 \mathrm{~h}$ before the next diffraction pattern was recorded. Subsequently, the temperature was increased stepwise at a rate of $2{ }^{\circ} \mathrm{C} / \mathrm{min}$. The sample was kept at each hold temperature step for 30 min before recording an XRD pattern, which itself took about $35 \mathrm{~min}$. After the final diffraction spectrum was captured at $700{ }^{\circ} \mathrm{C}$ the film was cooled down to room temperature at a rate of $5^{\circ} \mathrm{C} / \mathrm{min}$.

As seen in Fig. 1, the only difference between the XRD pattern recorded at room temperature and that recorded at $300{ }^{\circ} \mathrm{C}$ is the shift of the $\mathrm{SnO} 001\left(2 \theta=18.3^{\circ}\right)$ and 002 $\left(2 \theta=37.2^{\circ}\right)$ peaks towards a small $2 \theta$ value which is caused simply by the thermal expansion of the lattice constant on heating. This result indicates that there is no visible phase change occurring in the film up to $300^{\circ} \mathrm{C}$. Starting from $400{ }^{\circ} \mathrm{C}$, the intensity of the $\mathrm{SnO} 001$ and 002 reflections decreases and new peaks appear in the spectrum, which indicates that a phase transformation has occurred in the system. The broad peak at $31^{\circ}-34^{\circ}$ is a superposition of two reflections (peak 1 at $32.2^{\circ}$ and peak 2 at $33.1^{\circ}$ ). Comparing this XRD pattern with standard powder diffraction patterns for 


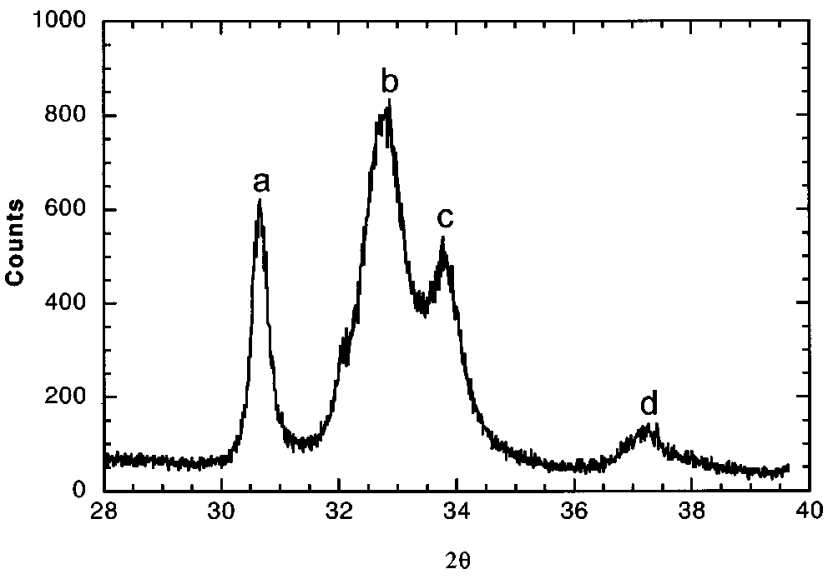

FIG. 2. High resolution XRD pattern taken from the film annealed at $500{ }^{\circ} \mathrm{C}$ for $5 \mathrm{~min}$, showing the appearance of several phases including $\mathrm{SnO}, \mathrm{Sn}_{3} \mathrm{O}_{4}$, and $\mathrm{SnO}_{2}$. (a) $\beta$-Sn 100 reflection, (b) $\mathrm{Sn}_{3} \mathrm{O}_{4} 003$ reflection, (c) $\mathrm{SnO}_{2} 101$ reflection, and (d) $\mathrm{SnO} 002$ reflection.

$\alpha$-SnO, $\mathrm{SnO}_{2}$, and other possible tin oxide phases, peak 2 represents the $\mathrm{SnO}_{2}(101)$ plane $\left(2 \theta\right.$ of $33.9^{\circ}$ at room temperature), while peak 1 may correspond to the 003 reflection of a metastable $\mathrm{Sn}_{3} \mathrm{O}_{4}$ phase ( $2 \theta$ of $32.9^{\circ}$ at room temperature). Upon further heating, the $\mathrm{SnO} 001$ and 002 peaks become shorter and broader and disappear at $500{ }^{\circ} \mathrm{C}$, while the intensities of peak 1 and peak 2 increase gradually. When the temperature is increased further, peak 1 starts to diminish and disappears at $\sim 600{ }^{\circ} \mathrm{C}$, whereas peak 2 continues to grow and becomes the only reflection from the film in the diffraction pattern, indicating the completion of the phase transformation from the $\alpha$-SnO to the rutile $\mathrm{SnO}_{2}$ phase.

From these in situ XRD studies we see that $\mathrm{Sn}_{3} \mathrm{O}_{4}$ is an intermediate phase in the temperature range between 400 and $500{ }^{\circ} \mathrm{C}$ during the phase transformation from $\mathrm{SnO}$ to $\mathrm{SnO}_{2}$. When the temperature increases above $500{ }^{\circ} \mathrm{C}$, the $\mathrm{Sn}_{3} \mathrm{O}_{4}$ phase is transformed into the rutile $\mathrm{SnO}_{2}$ phase. The XRD patterns in Fig. 1 show that most of the $\mathrm{Sn}_{3} \mathrm{O}_{4}$ phase has transformed into $\mathrm{SnO}_{2}$ at $600{ }^{\circ} \mathrm{C}$. Rutile $\mathrm{SnO}_{2}$ is the only phase visible in XRD patterns from the film annealed at $700{ }^{\circ} \mathrm{C}$. The final $\mathrm{SnO}_{2}$ film has an out-of-plane orientation relationship with respect to the substrate of $\mathrm{SnO}_{2}(101) \| \mathrm{Al}_{2} \mathrm{O}_{3}(\overline{1} 012)$.

It was reported in the literature that internal oxygen disproportionate distribution at intermediate temperatures ( $\sim 400-500{ }^{\circ} \mathrm{C}$ ) leads to metallic tin segregation during the heating and annealing processes. ${ }^{18}$ However, no reflection peaks corresponding to metallic tin were found in our in situ XRD study. Since the intensity of the x-ray diffractometer used for our in situ investigations was quite low, it was possible that the weak metallic tin reflection peaks could not be detected in that particular XRD apparatus. In order to elucidate the situation, a sample, which was cut from the same as-deposited film for the in situ XRD studies, was annealed at $500{ }^{\circ} \mathrm{C}$ for $5 \mathrm{~min}$ in a tube furnace at a heating and cooling rate of $10^{\circ} \mathrm{C} / \mathrm{min}$. A high resolution $\theta-2 \theta$ XRD pattern of this film was then recorded using a rotating anode four circle $\mathrm{x}$-ray diffractometer, as shown in Fig. 2. Peaks $b$ and $c$ correspond to the $\mathrm{Sn}_{3} \mathrm{O}_{4} 003$ reflection and $\mathrm{SnO}_{2} 101$ reflection,

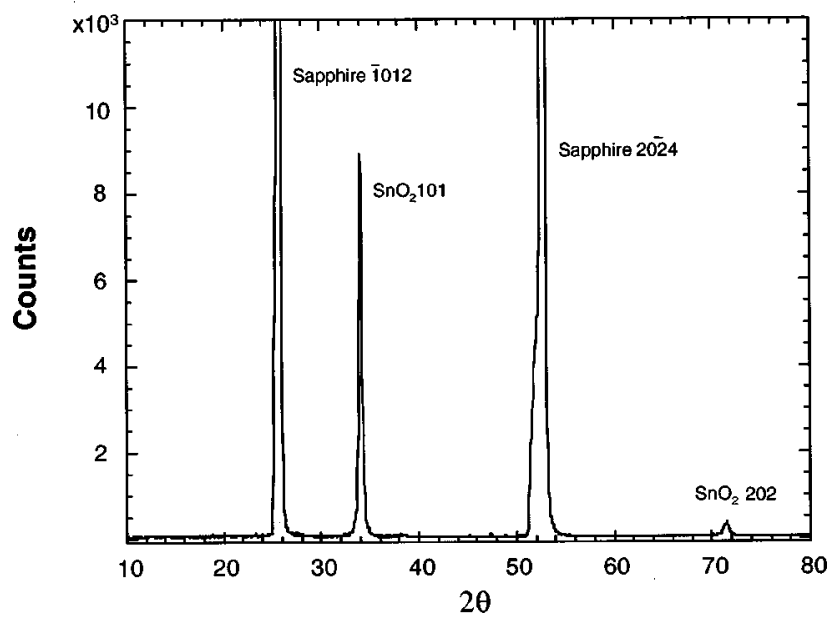

FIG. 3. $\theta-2 \theta$ scan taken at room temperature from the same sample as for Fig. 1 after finishing in situ XRD studies. Note that $\mathrm{SnO}_{2}$ is the only phase in the film and that an out-of-plane texture exists.

respectively. Peak $a$, located at $30.7^{\circ}$ in $2 \theta$, is identified to be the 100 reflection of $\beta$-Sn, which has a tetragonal structure. Peak $d$ is the reflection from the $\mathrm{SnO} 002$ plane. These results clearly show that metallic Sn precipitates indeed exist in the film at the intermediate stage of the $\mathrm{SnO}$ to $\mathrm{SnO}_{2}$ transformation process and that annealing at $500{ }^{\circ} \mathrm{C}$ for 5 min does not complete the transformation. Figure 3 is a highresolution $\mathrm{X}$-ray diffraction scan taken from the sample which was cooled down from $700{ }^{\circ} \mathrm{C}$ upon completion of the in situ XRD study, as previously described (see Fig. 1). Except for the strong peaks from the substrate, the only other visible reflections belong to $\mathrm{SnO}_{2} 101$ and 202, indicating that the $\mathrm{SnO}$ to $\mathrm{SnO}_{2}$ transformation is complete and that the film has a strong (101) texture.

Figure 4(a) is a plane-view TEM image taken from the specimen that was examined by in situ XRD used for Figs. 1 and 3. The average grain size in the film is about $100 \mathrm{~nm}$. The corresponding electron diffraction pattern is shown in Fig. 4(b), which was recorded with the electron beam aligned perpendicular to the sapphire substrate surface (1012). The diffraction pattern shows some high intensity spots located on the ring pattern of the rutile $\mathrm{SnO}_{2}$ structure. This indicates the existence of an in-plane texture in the $\mathrm{SnO}_{2}$ film. Figure 4(c) is a cross-section TEM micrograph taken from the same film. A laminar grain morphology is seen in the film. The average thickness of the laminas is about $20 \mathrm{~nm}$, which is much smaller than the lateral dimension $(\sim 100 \mathrm{~nm})$ as revealed by the plan-view and cross-section images in Figs. 4(a) and 4(c).

Many crystal defects, including twin boundaries and crystallographic shear planes (CSP), are found in the $\mathrm{SnO}_{2}$ film transformed from $\alpha$-SnO. Figure 5 is an HRTEM micrograph of the same specimen as shown in Fig. 4, showing the existence of defects. Twin boundaries and CSPs, indicated by arrows in the image, are normally located parallel to the $\mathrm{SnO}_{2}$ (101) plane, which is parallel to the film surface. Some of these defects terminate within crystallites. Many of the $\mathrm{SnO}_{2}$ crystallites are multiply twinned. The existence of multiply twinned nanocrystallites may result from deforma- 

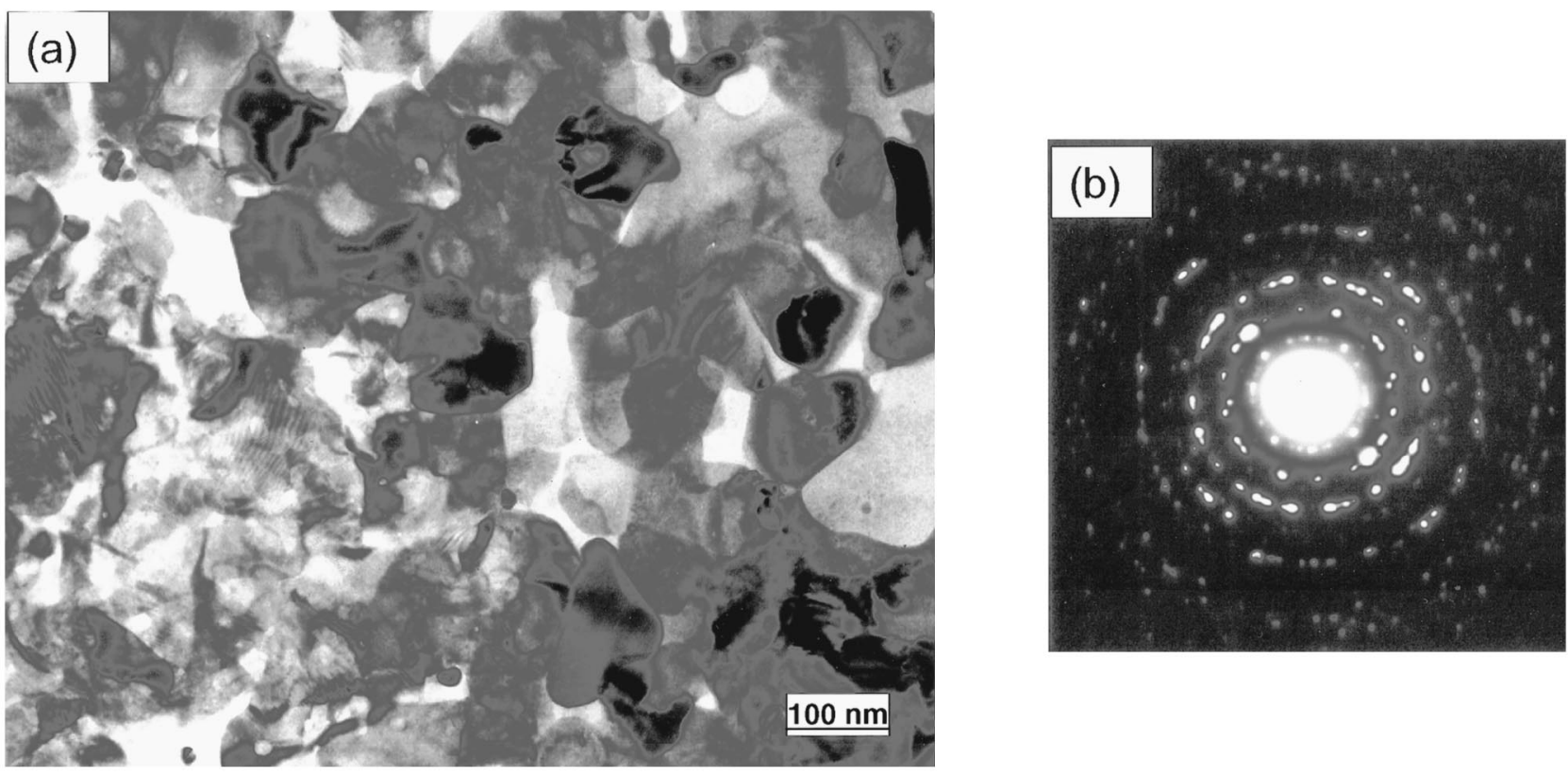

(c)

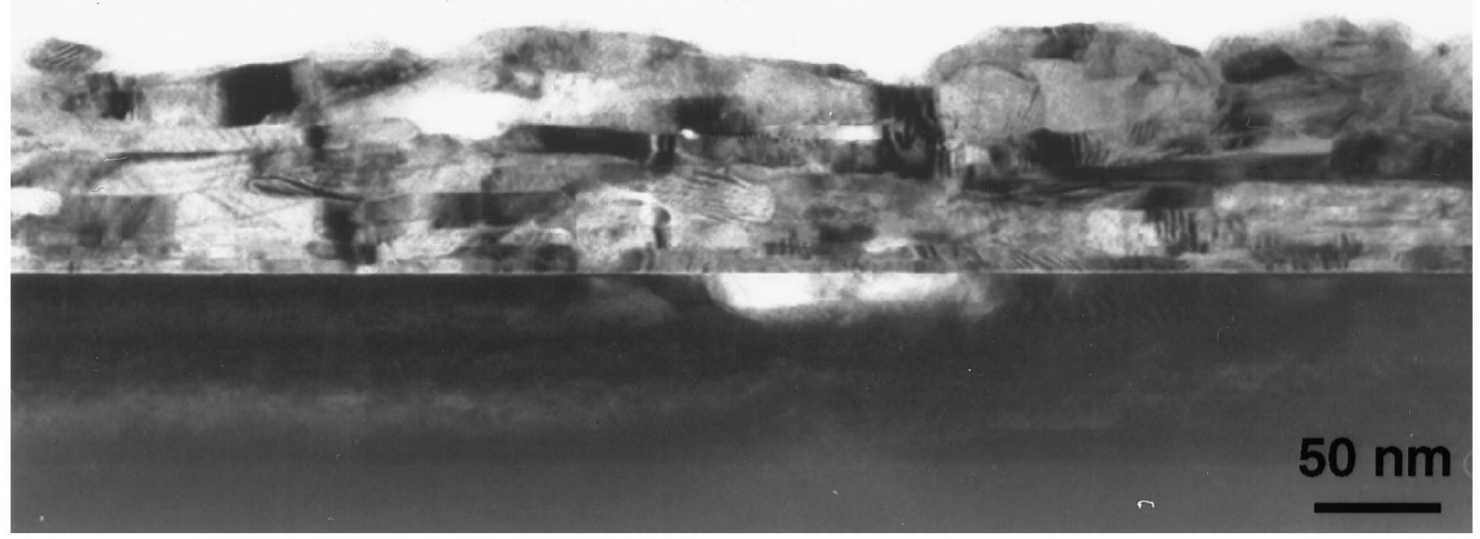

FIG. 4. (a) Plane-view TEM micrograph of the film annealed at $700{ }^{\circ} \mathrm{C}$, (b) corresponding selected area electron diffraction, and (c) cross-section micrograph of the same film. Note the layered microstructure of $\mathrm{SnO}_{2}$ films.

tion stresses applied on the $\mathrm{SnO}_{2}$ crystallites during the phase transformation from $\mathrm{SnO}$ to $\mathrm{SnO}_{2}$.

The microstructure evolution during the phase transformation of the film was also studied using TEM. Figure 6(a) shows a cross-sectional TEM image taken from the film annealed at $500{ }^{\circ} \mathrm{C}$ for $5 \mathrm{~min}$ (the sample examined for Fig. 2). We see that the film consists of regions with different microstructures. This feature is clearly shown in Fig. 6(b), which is an enlarged image from the region marked by a rectangle in Fig. 6(a). The area marked by the letter $\mathrm{R}$ is identified to be the rutile-type $\mathrm{SnO}_{2}$ phase which results in the strong Bragg spots in the electron diffraction pattern of the film, shown as an inset in the upper right corner of Fig. 6(b). The diffraction pattern also has diffused streaks and satellite spots along the film normal which are caused by regions in the film consisting of long, parallel lamellas as seen in Fig. 6(a). An example is shown in the middle region of Fig. 6(b), where there exist a number of closely spaced stacking faults. Some metastable phases with periodically spaced CSPs in the rutile lattice structure were observed due to oxygen deficiency in the film, which lead to the occurrence of satellite reflections in the electron diffraction pattern. Such metastable phases are similar to the defect structures found in nonstoichiometric $\mathrm{TiO}_{2-x} \cdot{ }^{20}$

Chemical compositions of the films were studied by XPS. Figure 7 shows XPS spectra for core levels Sn $3 d_{5 / 2}$, Sn $3 d_{3 / 2}$, and $\mathrm{O} 1 s$ of three films at different oxidation stages. The lower spectra in Figs. 7(a) and 7(b) were recorded from the epitaxial $\alpha$-SnO film before annealing, while the upper spectra were taken from the film which was studied by in situ XRD, as described previously. As shown before, XRD and TEM studies indicated that the latter sample consists of only a rutile $\mathrm{SnO}_{2}$ structure (see Figs. 1 and 3-5). The spectra in the middle were collected from the film that 


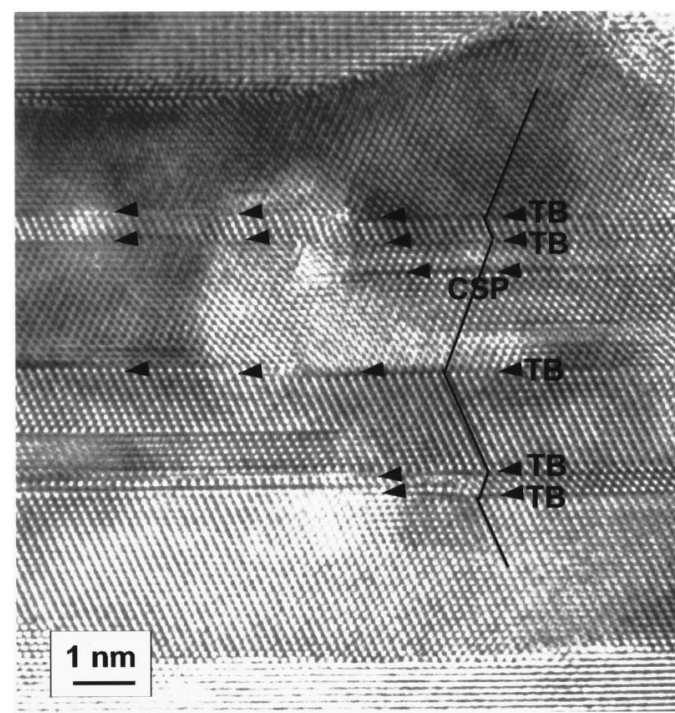

FIG. 5. HRTEM image of a $\mathrm{SnO}_{2}$ film showing the existence of crystal defects (twin boundary and crystallographic shear plane)

was annealed at $500{ }^{\circ} \mathrm{C}$ for 5 min. The corresponding XRD and TEM results are shown in Figs. 2 and 6. Comparing these XPS spectra, we see that the Sn $3 d_{5 / 2}$ and $3 d_{3 / 2}$ peaks are shifted toward high binding energy during the $\mathrm{SnO}-\mathrm{SnO}_{2}$ phase transformation, which corresponds to an increase of the work function (higher oxidation states) due to the difference in the coordination and bonding characteristics
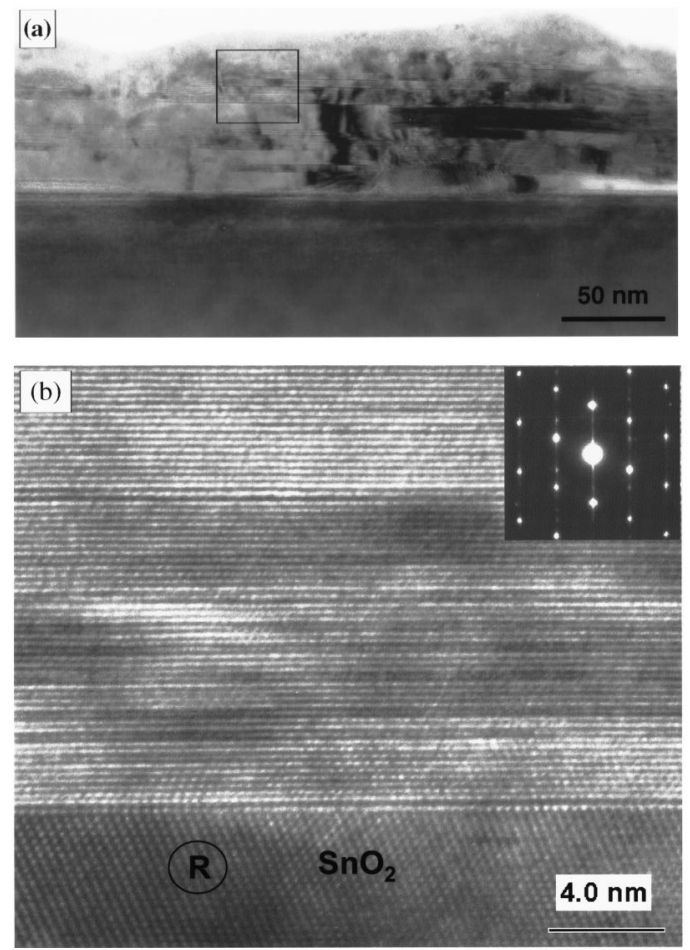

FIG. 6. (a) Cross-section TEM micrograph taken from the film annealed at $500{ }^{\circ} \mathrm{C}$ for $5 \mathrm{~min}$. (b) Enlarged image from the area marked by a square in (a). The layer indicated by $\mathrm{R}$ is identified to be the rutile type $\mathrm{SnO}_{2}$. The inset in the upper right-hand side of (b) shows the corresponding electron diffraction pattern.
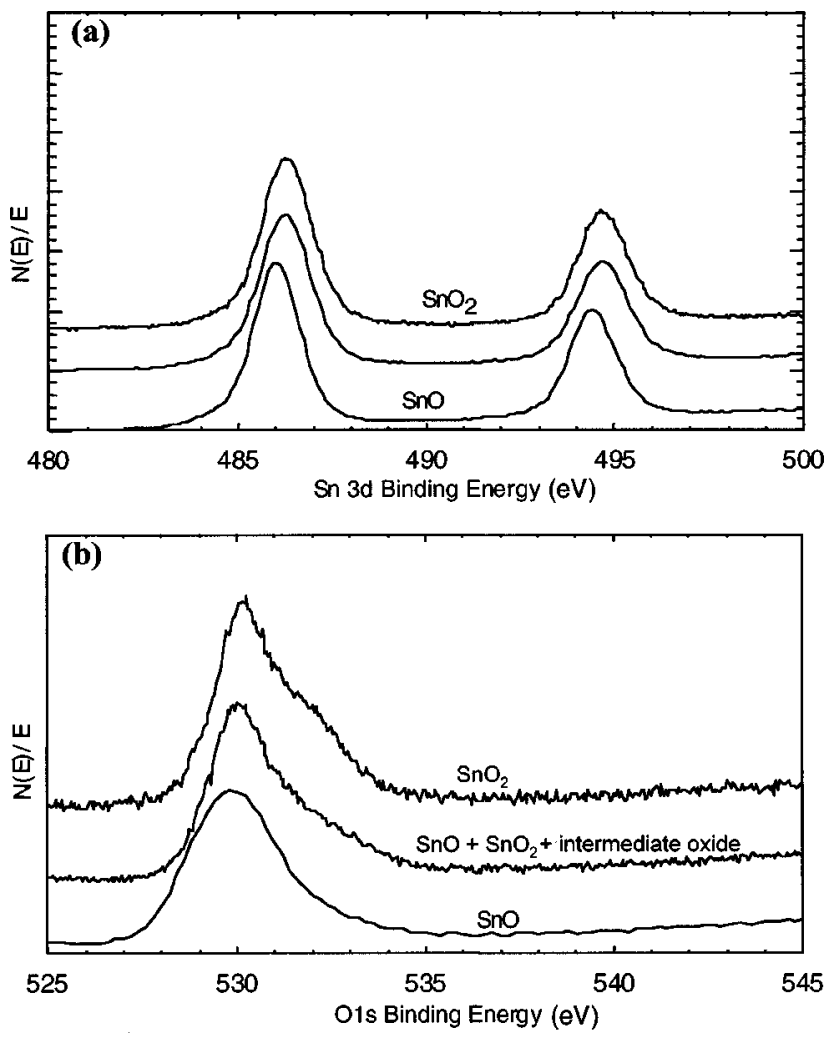

FIG. 7. XPS spectra showing the binding energy of Sn $3 d$ (a) and O $1 s$ (b).

of $\mathrm{Sn}$ in $\mathrm{SnO}$ and $\mathrm{SnO}_{2}$ phases. It has been reported that the $\mathrm{O} 1 s$ peak in oxides resides in the energy region of 529-532 $\mathrm{eV}^{21}$ The peak around 529 to $530 \mathrm{eV}$ is commonly ascribed to lattice oxygen. Ghuang et al. ${ }^{22}$ found that the peak around $530.7-531.6 \mathrm{eV}$ is caused by oxygen inside nonstoichiometric oxides within the surface region of the material. Srinivasan et al. ${ }^{23}$ ascribed the peak at $531.7 \mathrm{eV}$ to be chemisorbed oxygen on the surface. According to these studies, the

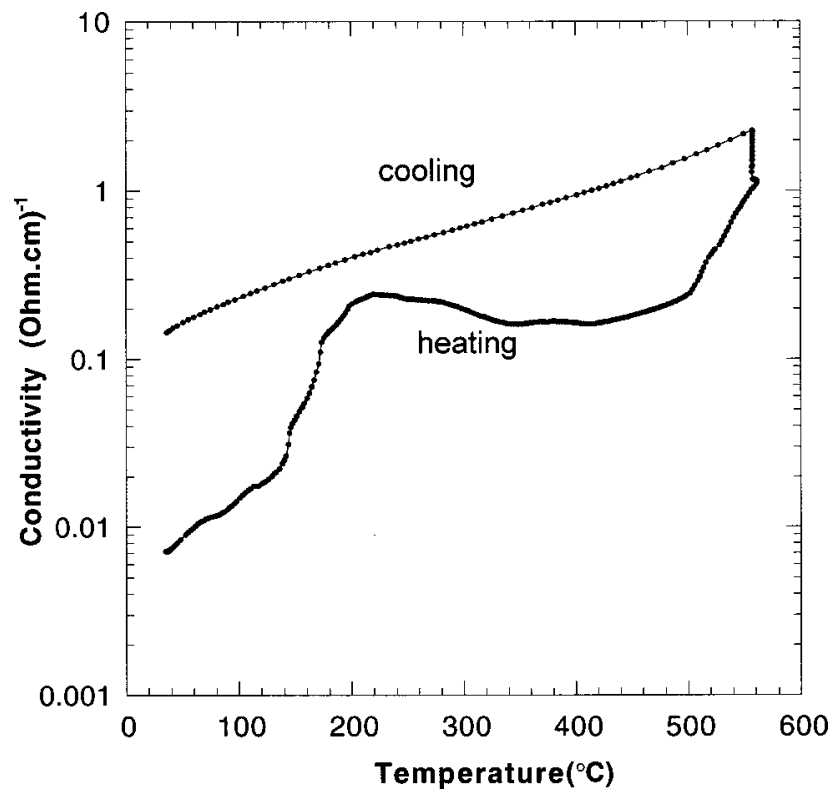

FIG. 8. Electrical conductivity of tin oxide film as a function of temperature on heating and cooling. 


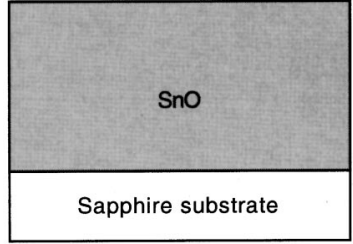

(a)

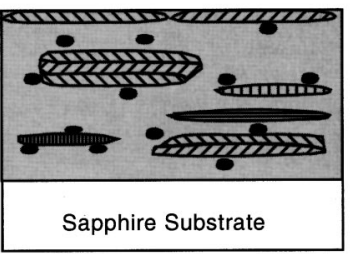

(c)

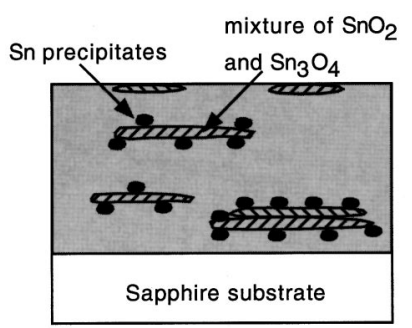

(b)

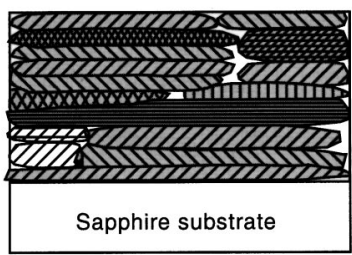

(d)
FIG. 9. Schematics showing the $\mathrm{SnO}-\mathrm{SnO}_{2}$ structural transformation during heating in air. (a) as-deposited film, (b) oxygen disproportionation inside the film, (c) growth of the laminas and oxygen diffusion, and (d) final $\mathrm{SnO}_{2}$ film.

peaks at $530 \mathrm{eV}$ in Fig. 7(b) can be attributed to lattice oxygen in the tin oxide films. The nonsymmetric part of the $\mathrm{O}$ $1 s$ peak around $532 \mathrm{eV}$ may be due to chemisorbed oxygen on the surface of $\mathrm{SnO}_{2}$ crystallites in the annealed film. The relative concentrations of the constituent elements in the films were calculated by utilizing peak area sensitivity factors. The $[\mathrm{Sn}] /[\mathrm{O}]$ ratio was found to be $49.2 / 50.8,42.4 / 57.6$, and $32.3 / 67.7$ for the as-grown film, the film annealed at $500{ }^{\circ} \mathrm{C}$ and the film annealed at $700{ }^{\circ} \mathrm{C}$, respectively.

Electrical transport properties of the tin oxide film were performed by both electrical conductivity measurements and Hall effect measurements at different temperatures during annealing in synthesized air. The measurements were conducted using a four-point probe (van der Pauw) method. The as-grown epitaxial $\mathrm{SnO}$ film was heated from ambient temperature $\left(\sim 22{ }^{\circ} \mathrm{C}\right)$ to $560{ }^{\circ} \mathrm{C}$ at a rate of $2 \% \mathrm{~min}$ and held at this temperature for $10 \mathrm{~h}$. The cooling run was also conducted at a rate of $-2 \% \mathrm{~min}$. The conductivity as a function of temperature was recorded during heating and cooling, as shown in Fig. 8. Up to $200{ }^{\circ} \mathrm{C}$ during heating, film conductivity increased with the increase of temperature. However, the slope of the conductivity-temperature $(\sigma-T)$ curve changed at $\sim 140{ }^{\circ} \mathrm{C}$. Above $140{ }^{\circ} \mathrm{C}$, the conductivity rapidly increased with increasing temperature. When heated to about $200{ }^{\circ} \mathrm{C}$, the slope of the curve changed again and the conductivity slightly decreased with the further increase of temperature up to $\sim 400{ }^{\circ} \mathrm{C}$. Subsequently, the conductivity increased with increasing temperature. On cooling, after annealing at $560{ }^{\circ} \mathrm{C}$ for $10 \mathrm{~h}$, the film showed a conductivity-temperature relationship of $\sigma=\sigma_{0} \exp (E / k T)$, which is a typical feature for a rutile type $\mathrm{SnO}_{2}$ film. After the film was cooled down to room temperature, the XRD $(\theta-2 \theta)$ pattern was recorded. The diffraction pattern (not shown here) is similar to that shown in Fig. 3, indicating that the film consists of the rutile $\mathrm{SnO}_{2}$ phase. The Hall measurements were also conducted on the same as-deposited film

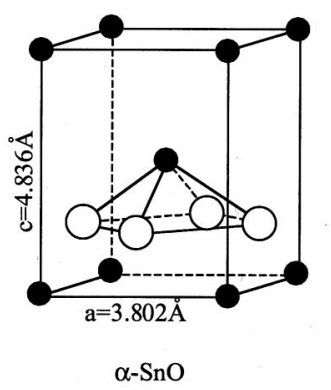

(a)

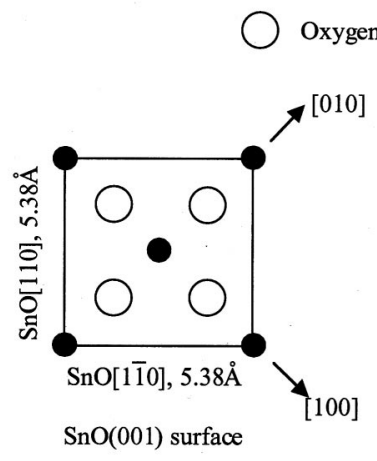

(c)

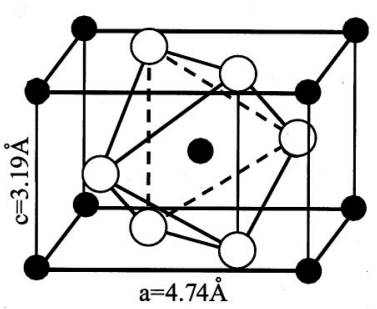

$\mathrm{SnO}_{2}$

(b)

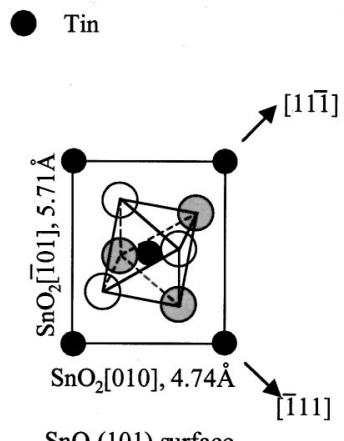

(d)
FIG. 10. (a) Unit cell of $\mathrm{SnO}$, (b) unit cell of $\mathrm{SnO}_{2}$, (c) atomic configurations of the $\mathrm{SnO}(001)$ surface, and (d) atomic configurations of the $\mathrm{SnO}_{2}$ (101) surface.

from ambient temperature to $375^{\circ} \mathrm{C}$. It was found that the film shows the typical transport behavior of a $p$-type semiconductor up to $350^{\circ} \mathrm{C}$ and the combined effects of both $p$ and $n$-type semiconductors above such temperature.

\section{DISCUSSION}

The experimental results described above show that epitaxial $\alpha$-SnO film grown on (1012) $\alpha-\mathrm{Al}_{2} \mathrm{O}_{3}$ substrate is unstable in oxygen atmosphere at high temperature and will transform into the rutile $\mathrm{SnO}_{2}$ phase through an oxidation process. If the phase transformation in the epitaxial $\mathrm{SnO}$ film proceeds only through the diffusion of oxygen from annealing atmosphere, the phases with high oxidation states $\left(\mathrm{Sn}_{3} \mathrm{O}_{4}\right.$ and $\mathrm{SnO}_{2}$ ) should mainly be located near the film surface at the initial stage and the metallic tin phase should not form in the film. However, the XRD results of the partially oxidized film clearly demonstrate the coexistence of the rutile $\mathrm{SnO}_{2}$ phase with many other intermediate products, such as $\mathrm{Sn}_{3} \mathrm{O}_{4}$ and metallic tin. Cross-section TEM studies of the film quenched from the intermediate annealing stage also show that rutile $\mathrm{SnO}_{2}$ and other intermediate oxidation products are distributed randomly in the film. This means that the oxidation of the $\mathrm{SnO}$ film proceeds both through the surface reaction with atmospheric oxygen and through internal oxidation by local disproportionate oxygen distribution. The latter process is particularly important at relatively low temperature at which oxygen diffusion in the crystal lattice is slow. As proposed by Geurts et al., ${ }^{18}$ this process can be considered as 


$$
(1+x) \mathrm{SnO} \rightarrow x \mathrm{Sn}+\mathrm{SnO}_{1+x} .
$$

This reaction leads to the coexistence of $\mathrm{SnO}$ with higher oxidation states $\left(\mathrm{Sn}_{3} \mathrm{O}_{4}\right.$ and $\left.\mathrm{SnO}_{2}\right)$ and precipitation of the metallic tin phase. Further oxidation requires additional oxygen to transform $\mathrm{SnO}_{x}$ and metallic $\mathrm{Sn}$ into the rutile $\mathrm{SnO}_{2}$. This process becomes more efficient when the temperature is increased, due to enhanced oxygen diffusion at high temperatures. The mechanisms of the $\mathrm{SnO}-\mathrm{SnO}_{2}$ structural transformation discussed are schematically shown in Figs. 9(a) -9 (d).

Both XRD and TEM studies show that the $\mathrm{SnO}_{2}$ film obtained by annealing at high temperature consists of a (101) texture. To understand the formation mechanism of the (101) texture in $\mathrm{SnO}_{2}$ film, it is necessary to study the atomic structures of both $\alpha-\mathrm{SnO}$ and $\mathrm{SnO}_{2}$. Both of these materials are tetragonal, and the unit cells of both structures are shown in Figs. 10(a) and 10(b). In the rutile $\mathrm{SnO}_{2}$ structure each $\mathrm{Sn}$ atom has six nearest oxygen neighbors, which form a distorted octahedron. Sn atoms fill the center of the oxygen octahedra. The distance between $\mathrm{Sn}$ and $\mathrm{O}$ atoms within one octahedron is $2.057 \AA$. On the other hand, $\alpha$-SnO has a layered atomic structure, similar to that of $\mathrm{PbO}$. Each $\mathrm{Sn}$ atom has four nearest oxygen neighbors, but all of these oxygen atoms are located on the same side of the Sn atom, as shown by the pyramid consisting of one $\mathrm{Sn}$ atom and four $\mathrm{O}$ atoms in the $\mathrm{SnO}$ unit cell [Fig. 10(a)]. The $\mathrm{Sn}-\mathrm{O}$ bond has a length of $2.223 \AA$.

There is a marked similarity between the (001) surface of $\mathrm{SnO}$ and the (101) surface of $\mathrm{SnO}_{2}$, as shown in Figs. 10(c) and (d). In Fig. 10(c), oxygen atoms are located at the same level above the Sn atomic layer. Oxygen atoms, shown as open circles and shaded circles in Fig. 10(d) are located, respectively, below and above the Sn (closed small circles) atomic layer. It can be seen that when a (101) epilayer of the rutile $\mathrm{SnO}_{2}$ phase forms on the $\mathrm{SnO}$ (001) surface, only a small distortion of $\mathrm{Sn}$ sublattice is required. However, the oxygen configurations on $\mathrm{SnO}(001)$ and $\mathrm{SnO}_{2}$ (101) surfaces are quite different. Due to the onefold symmetry on the (101) $\mathrm{SnO}_{2}$ surface and fourfold symmetry on the (001) $\mathrm{SnO}$ surface, four different rotational variants of $\mathrm{SnO}_{2}$ phase may occur in the film: $[010](101)_{\mathrm{SnO}_{2}} \|[1 \overline{1} 0](001)_{\mathrm{SnO}}$ and its three variants by rotation around the $\mathrm{SnO}[001]$ axis by $\pm 90^{\circ}$ and $180^{\circ}$. The growth of the new $\mathrm{SnO}_{2}$ phase proceeds through oxygen diffusion through the crystal lattice and requires the reconstruction of the oxygen sublattice for the $\mathrm{SnO}$ phase. It is known that the (101) surface of $\mathrm{SnO}_{2}$ has a low surface energy. It is also seen in Fig. 10(a) that $\alpha$-SnO has a (001) layered structure in the oxygen sublattice. These factors indicate that the structural transformation is controlled by the $\mathrm{SnO}-\mathrm{SnO}_{2}$ interface. This in turn leads to the formation of a flat $\mathrm{SnO}-\mathrm{SnO}_{2}$ interface and the development of the low surface energy (101) texture in $\mathrm{SnO}_{2}$.

The formation of $\mathrm{SnO}_{2}$ (101) orientated laminas in the films can be explained based on the oxidation mechanisms and the interface-controlled growth mechanism of the $\mathrm{SnO}_{2}$ phase. During the initial stages of oxidation, a combination of the disproportionate redistribution of internal oxygen and the diffusion of external oxygen permits multiple phases ( $\mathrm{Sn}$,
$\mathrm{SnO}, \mathrm{Sn}_{3} \mathrm{O}_{4}$, and $\mathrm{SnO}_{2}$ ) to coexist in the film. As discussed previously, the growth of the localized $\mathrm{SnO}_{2}$ phase within the film is controlled by the $(101)_{\mathrm{SnO}_{2}} \|(001)_{\mathrm{SnO}}$ interface. Therefore a laminar shape of the $\mathrm{SnO}_{2}$ crystallites is expected. This prediction is consistent with direct cross-section TEM observations, as shown in Fig. 6. As the temperature is increased, external oxygen can diffuse into the film. The $\mathrm{SnO}_{2}$ crystallites will grow at the expense of intermediate product phases such as $\mathrm{Sn}_{3} \mathrm{O}_{4}$ and metallic tin, but the laminar shape of $\mathrm{SnO}_{2}$ grains will remain because of the low surface energy of the (101) surface. For $\mathrm{SnO}_{2}$ grains formed directly on the original $\alpha$-SnO phase, four different in-plane orientation relationships with respect to $\mathrm{SnO}$ may exist, as discussed previously. These orientation relationships explain the diffraction spots with high intensities in Fig. 4(b). However, the $\mathrm{SnO}_{2}$ grains transformed from the intermediate phases, such as $\mathrm{Sn}$ and $\mathrm{Sn}_{3} \mathrm{O}_{4}$ phases, may not have in-plane texture. As a result, the electron diffraction of the annealed film also consists of a ring pattern, as shown in Fig. 4(b).

Conductivity change during heating is related to both structure and composition changes in the film. The corresponding Hall measurements show that $\alpha$-SnO is a $p$-type semiconductor. Electrical conduction in the material comes from the excess of oxygen, as described in previous studies. ${ }^{17}$ On the other hand, $\mathrm{SnO}_{2}$ is an $n$-type semiconductor and the electrical carriers (electrons) are caused by the existence of oxygen vacancies in the material. Since oxygen concentration plays an important role in the conduction mechanism of both materials, it is obvious that the anneal processes in oxygen atmosphere will have an effect on the conductivity of the film. According to the in situ XRD studies, $\mathrm{SnO}$ is the major phase at low temperature up to about $300{ }^{\circ} \mathrm{C}$. The increase of film conductivity below $140^{\circ} \mathrm{C}$ is due to the thermal activation of the $p$-type semiconductor $\mathrm{SnO}$. The change in the slope of the $\sigma-T$ curve at $140{ }^{\circ} \mathrm{C}$ may be caused by the activation of chemical reactions between adsorbed oxygen atoms and $\mathrm{SnO}$ surfaces. This reaction can cause the increase of oxygen concentration and thus create a number of holes near SnO surfaces, which leads to the increase of electrical conductivity.

Above $200^{\circ} \mathrm{C}$, although the oxygen diffusion in the crystal lattice is limited, $\mathrm{SnO}_{2}$ phases can form at the film surface due to reactions with chemisorbed oxygen on the surface. This was confirmed by the cross-section TEM studies of a SnO film annealed in air at $200^{\circ} \mathrm{C}$ for $2 \mathrm{~h}$, showing a number of small $\mathrm{SnO}_{2}$ crystallites at the film surface. With a further increase in temperature, an internal oxidation process occurs due to the localized disproportionate redistribution of oxygen in $\mathrm{SnO}$ film, as revealed by in situ XRD studies. This internal oxidation process leads to the formation of metallic tin, $\mathrm{Sn}_{3} \mathrm{O}_{4}$, and $\mathrm{SnO}_{2}$. The $\mathrm{SnO}_{2}$ crystallites formed during such internal oxidation processes are usually deficient in oxygen due to a low oxygen concentration of the film ([Sn]/[O] ratio close to one). Thus they are an $n$-type semiconductor. On the other hand, the existence of small metallic tin precipitates and laminar $\mathrm{SnO}_{2}$ crystallites in a $p$-type $\alpha$-SnO matrix will form a number of phase boundaries (interfaces) in the film. A number of $p$ - $n$ junctions (depleted of electrical carriers) will form at the interfaces be- 
tween the $\mathrm{SnO}_{2}$ crystallites and the $\mathrm{SnO}$ matrix. Similarly, Schottky barriers will be formed between the $n$-type semiconductive $\mathrm{SnO}_{2}$ crystallites and metallic Sn precipitates. As a consequence of the formation of $p$ - $n$ junctions and Schottky barriers, both the concentration and the mobility of electrical carriers in the film will be reduced. These processes subsequently lead to the decrease of conductivity with the increase of temperature. With a further increase in the temperature, the oxidation process becomes fast due to external oxygen diffusion from the film surface. The $\mathrm{SnO}_{2}$ crystallites grow rapidly at the expense of other phases with low oxidation states and thereby become the major phase in the film. Due to the vanishing of the $\mathrm{SnO}$ phase and tin precipitates, the effect of $p$ - $n$ junctions and Schottky barriers on electrical transport behavior becomes small. Therefore the conductivity of the film is expected to increase with increasing temperature (see the $\sigma-T$ curve above $500{ }^{\circ} \mathrm{C}$ in Fig. 8). After annealing at $560^{\circ} \mathrm{C}$ for $10 \mathrm{~h}$, the film shows typical $n$-type semiconductor behavior on cooling (see Fig. 8).

\section{CONCLUSIONS}

Structural evolution and electrical conduction characteristics of epitaxial $\alpha$-SnO thin films grown on (1012) sapphire $\left(\alpha-\mathrm{Al}_{2} \mathrm{O}_{3}\right)$ substrate have been studied in detail by different characterization methods. In situ x-ray diffraction studies showed that this metastable phase transforms into $\mathrm{SnO}_{2}$ with the rutile type structure when heated to high temperatures in oxygen atmosphere. The transformation begins at about $300{ }^{\circ} \mathrm{C}$ on heating. In the initial stage of the oxidation processes, the rutile $\mathrm{SnO}_{2}$ phase coexists with the $\alpha$-SnO phase and intermediate products such as $\mathrm{Sn}$ and $\mathrm{Sn}_{3} \mathrm{O}_{4}$. After being annealed at temperatures above $600^{\circ} \mathrm{C}$, the film is fully transformed into the rutile $\mathrm{SnO}_{2}$ phase. The transformation proceeds through the local disproportionate redistribution of internal oxygen at low temperature, followed by the transformation of the remaining $\mathrm{SnO}$ phase and the intermediate phases into $\mathrm{SnO}_{2}$ through the inward diffusion of external oxygen at higher temperatures. The formation and growth of $\mathrm{SnO}_{2}$ crystallites in the $\alpha$-SnO film are controlled by the $(101)_{\mathrm{SnO}_{2}} \|(001)_{\mathrm{SnO}}$ interfaces, leading to a (101) texture and a laminar grain shape of $\mathrm{SnO}_{2}$. The electrical conduction characteristics were related with events pertinent to the structural evolution of the film.

\section{ACKNOWLEDGMENTS}

The authors gratefully acknowledge the financial support of the National Science Foundation DMR 9875405 (CAREER-XQP), the Petroleum Research Fund No. 34093G5, the College of Engineering at the University of Michigan, and the Applied Materials Company (Santa Clara, CA).

${ }^{1}$ Sensors-A Comprehensive Survey, edited by W. Göpel, J. Hesse, and J. N. Zemel (VCH Weinheim, New York, 1991), Vol. 2.

${ }^{2} \mathrm{~K}$. Ihokura and J. Watson, The Stannic Oxide Gas Sensor-Principles and Applications (CRC, Boca Raton, FL, 1994).

${ }^{3}$ G. Advani and A. Jordan, J. Electrochem. Soc. 123, 29 (1990).

${ }^{4} \mathrm{~N}$. Yamazoe, Proceedings of the Third International Meeting Chem. Sensors, Cleveland, OH, 1990, pp. 3-8.

${ }^{5}$ C. Xu, J. Tamaki, M. Miur, and N. Yamazoe, Sens. Actuators B 3, 147 (1991).

${ }^{6}$ W. Göpel and K. D. Schierbaum, Sens. Actuators B 26-27, 1 (1995).

${ }^{7}$ J.-G. Zheng, X. Q. Pan, M. Schweizer, U. Weimar, W. Göpel, and M. Rühle, Philos. Mag. Lett. 73, 93 (1996).

${ }^{8}$ J.-G. Zheng, X. Q. Pan, M. Schweizer, F. Zhou, U. Weimar, W. Göpel, and M. Rühle, J. Appl. Phys. 79, 7688 (1996).

${ }^{9}$ J.-G. Zheng, X. Q. Pan, M. Schweizer, U. Weimar, W. Göpel, and M. Rühle, J. Mater. Sci. 31, 2317 (1996).

${ }^{10}$ X. Q. Pan and J. G. Zheng, Mater. Res. Soc. Symp. Proc. 472, 87 (1997).

${ }^{11}$ N. Y. Shishkin, I. M. Zharsky, V. G. Lugin, and V. G. Zarapin, Sens. Actuators B 48, 403 (1998).

${ }^{12}$ M. C. Horrillo, P. Serrini, J. Santos, and L. Manes, Sens. Actuators B 45, 193 (1997).

${ }^{13}$ S. Semancik and R. E. Cavicchi, Thin Solid Films 206, 81 (1991).

${ }^{14}$ M. H. Reddy and A. N. Chandorkar, Sens. Actuators B 9, 1 (1992).

${ }^{15}$ W. I. Cho, H. Jang, and S. R. Lee, Scr. Metall. Mater. 32, 815 (1995).

${ }^{16}$ M. H. Reddy, S. R. Jawalekar, and A. N. Chandorkar, Thin Solid Films 169, 117 (1989)

${ }^{17}$ L. Fu and X. Q. Pan, J. Electroceram. (submitted).

${ }^{18}$ J. Geurts, S. Rau, W. Richter, and F. J. Schmitte, Thin Solid Films 121, 217 (1984).

${ }^{19}$ M. R. Soares, P. H. Dionisio, I. J. R. Baumvol, and W. H. Schreiner, Thin Solid Films 214, 6 (1992).

${ }^{20}$ L. A. Bursill and B. G. Hyde, Acta Crystallogr., Sect. B: Struct. Crystallogr. Cryst. Chem. B27, 210 (1971).

${ }^{21}$ C. D. Wagner, W. M. Riggs, L. E. Davis, and J. F. Moulder, Handbook of $X$-ray Photoelectron Spectroscopy (Perkin-Elmer Corporation, Minnesota).

${ }^{22}$ T. J. Chuang, C. R. Brundle, and D. W. Rice, Surf. Sci. 59, 413 (1976).

${ }^{23}$ A. Srinivasan, K. Jagannathan, M. S. Hedge, and C. N. R. Rao, Indian J. Chem. A 18, 463 (1979). 